Brit. J. industr. Med., 1953, 10, 164.

\title{
NIGHT WORK AND SHIFT CHANGES
}

\author{
BY \\ S. WYATT and R. MARRIOTT \\ From The Medical Research Council Group for Research in Industrial Psychology
}

(RECEIVED FOR PUBLICATION JANUARY 2, 1953)

It is generally recognized that night work is undesirable and is only permissible when strictly necessary, as in some continuous operations or in times of emergency. Objections to night work have been made on medical, social, and economic grounds, and the latter aspects of the problem were studied in some detail by the Health of Munition Workers Committee (1918) during the 1914-18 war. This Committee found no significant difference between the rates of output of men employed on alternate day and night shifts and recommended this system in preference to continuous night work. Alternate day and night work was also shown to be only slightly inferior, as regards output, to continuous day work, while from the standpoint of lost time it was better than day work.

These findings refer mainly to a weekly change of shifts but in many factories shifts are changed every fortnight and in some every month. The frequency of shift changes is clearly a matter of some importance, but evidence of the effects of these changes and their relation to the problems of night work is very meagre. Some figures "collected by Vernon for the Health of Munition Workers Committee (1917) showed that, when shifts were changed fortnightly, output was slightly higher and absenteeism less during the first week on the night shift than during the second week. The corresponding figures for the day shift showed, if anything, the opposite tendency.

In a survey of the literature relating to the effects of night work on health and efficiency Teleky (1943) concludes that night work causes an inversion of the body temperature curve which, for most factory workers, takes place within a week. After changing back to day work the reversion to normal is more rapid than the inversion. Teleky thinks that these periods of inversion and reversion of body temperature may be associated with increased physiological strain and tentatively suggests a monthly rather than a weekly change of shifts. The Health of Munition Workers Committee also emphasized the physiological advantages of infrequent shift changes but recognized that it might be difficult to reconcile these advantages with personal desires and social claims.

This paper describes a preliminary study in which we attempted to define more precisely the nature of the factors involved in night work and shift changes and to indicate their probable effects. It was realized at the outset that conclusive evidence could only be obtained by studying the same group of workers employed on different shift sequences but the facilities and conditions necessary for such a study could not be found. As an alternative, it was decided to conduct a limited inquiry in three factories (A, B, and C) having a weekly, a fortnightly, and a monthly change of shifts respectively and so to prepare the way, if necessary, for a more extensive investigation later. The inquiry was limited to male workers and most of the information was collected in 1945-46. Factory $A$ made railway wagon wheels, factory B was a rolling mill, and factory C made motor vehicles.

The general procedure was to collect all the available records of output, accidents, and absence from work which might provide reliable information on the merits and defects of night work and the frequency of shift changes. In addition, a number of men in each of the three factories were interviewed in order to ascertain their attitudes to various aspects of the problem.

\section{Output}

Output records should show the relative efficiency of day and night work and also whether efficiency increases or decreases for some time after the change of shifts. In order to demonstrate these possibilities, it is necessary for individual workers to be employed on the same process throughout the experimental period. Further, the cycle of operations for each unit of output must be fairly short, easily measurable, and reflect working capacity. In this investi- 
gation very few of the processes were found to satisfy these conditions. An exhaustive search in the three main factories yielded output records from a small number of men in Factory A, none in Factory $\mathrm{B}$, and a few specially recorded figures in Factory $\mathrm{C}$; hence the amount of evidence included in this section fell far short of expectations. It has, however, been supplemented by a few output figures collected from groups of workers employed on machining operations in other factories.

A general comparison of the average hourly output on day and night work is given in Table 1 .

TABLE 1

RELATIVE HOURLY OUTPUT OF MEN ON DAY AND NIGHT SHIFTS OF THE TWO-SHIFT SYSTEM

\begin{tabular}{|c|c|c|c|c|c|}
\hline \multirow{2}{*}{$\begin{array}{l}\text { Factory } \\
\text { Group }\end{array}$} & \multirow{2}{*}{$\begin{array}{c}\text { Shifis } \\
\text { Changed }\end{array}$} & \multirow{2}{*}{$\begin{array}{l}\text { Length } \\
\text { of } \\
\text { Period } \\
\text { (weeks) }\end{array}$} & \multirow{2}{*}{$\begin{array}{l}\text { No. of } \\
\text { Workers }\end{array}$} & \multicolumn{2}{|c|}{$\begin{array}{l}\text { Relative Hourly } \\
\text { Output* }\end{array}$} \\
\hline & & & & $\begin{array}{l}\text { Day } \\
\text { Shift }\end{array}$ & $\begin{array}{c}\text { Night } \\
\text { Shift }\end{array}$ \\
\hline $\begin{array}{l}\mathbf{A} \\
\mathbf{D} \\
\mathbf{E}\end{array}$ & $\begin{array}{c}\text { Weekly } \\
,, \\
,,\end{array}$ & $\begin{array}{r}16 \\
8 \\
18\end{array}$ & $\begin{array}{l}41 \\
16 \\
82\end{array}$ & $\begin{array}{r}99.97 \\
100.81 \\
100.46\end{array}$ & $\begin{array}{r}100 \cdot 03 \\
99 \cdot 19 \\
99.54\end{array}$ \\
\hline \multicolumn{3}{|c|}{ Average of 3 factory groups } & . & $100 \cdot 41$ & $99 \cdot 59$ \\
\hline $\begin{array}{l}\mathbf{F} \\
\mathbf{G} \\
\mathbf{H}\end{array}$ & $\begin{array}{c}\text { Fortnightly } \\
,, \\
, "\end{array}$ & $\begin{array}{l}8 \\
8 \\
4 \\
4\end{array}$ & $\begin{array}{r}105 \\
72 \\
75 \\
53\end{array}$ & $\begin{array}{r}100 \cdot 17 \\
101 \cdot 13 \\
100 \cdot 25 \\
99 \cdot 88\end{array}$ & $\begin{array}{r}99 \cdot 83 \\
98 \cdot 87 \\
99 \cdot 75 \\
100 \cdot 12\end{array}$ \\
\hline \multicolumn{3}{|c|}{ Average of 4 factory groups } & . & $100 \cdot 38$ & $99 \cdot 64$ \\
\hline $\begin{array}{l}\mathbf{C} \\
\mathbf{J} \\
\mathbf{K}\end{array}$ & $\begin{array}{c}\text { Monthly } \\
,,\end{array}$ & $\begin{array}{l}8 \\
8 \\
8\end{array}$ & $\begin{array}{l}45 \\
41 \\
25\end{array}$ & $\begin{array}{l}101 \cdot 13 \\
100 \cdot 47 \\
100 \cdot 71\end{array}$ & $\begin{array}{l}98 \cdot 87 \\
99 \cdot 53 \\
99 \cdot 29\end{array}$ \\
\hline \multicolumn{3}{|c|}{ Average of 3 factory groups } & $\ldots$ & $100 \cdot 77$ & $99 \cdot 23$ \\
\hline
\end{tabular}

*Expressed as a percentage of the average hourly output on both shifts combined.

The figures show that the average hourly output was slightly higher on the day shift than on the night shift. In each factory group the weekly hours of work were approximately the same on both the day and night shifts but as there were five and a half day shifts and five night shifts per week the daily hours were usually a little shorter on the day shift than on the night shift. The average hourly output on Saturday morning was from 11 to $15 \%$ less than the average from Monday to Friday, and the exclusion of this relatively unproductive period from the day shift averages in Table 1 would increase the difference between the day and night averages. A majority of the workers was also employed on semi-automatic machines which, unlike handwork, fail to reflect the full effect of changes in working capacity on output.

Although the figures in Table 1 show that the rate of working tended to be higher on the day shift than on the night shift, it would be rash to infer that night work was more fatiguing than day work. It may be, but the lower rate on the night shift could also be due to other factors. There is a fairly widespread belief, and some of the figures collected in this inquiry support the view, that many workers aim at a fixed weekly wage and regulate their output accordingly. Such workers could afford to reduce their rate of working on the night shift and yet earn the same weekly wage because of the higher basic rate.

Nevertheless a substantial majority of the workers in each factory group consistently produced more per hour on the day shift than on the night shift. Most of the remainder consistently showed the opposite tendency. Further, out of a total of 150 men who were closely questioned on their attitude to day and night work, $68 \%$ claimed that they worked better on the day shift than on the night shift ; $21 \%$ noticed no marked difference, and the remaining $11 \%$ found the night shift better for output. The attitude of these men to day and night work seemed to be closely related to the disturbing effects of night work on eating and sleeping habits ; the greater the effect, the stronger was the preference for day work. These observations support the hypothesis that, to a majority of workers, night work needs more effort and is more tiring than day work and hence strengthen the probability that the differences in Table 1 were due to increased fatigue on the night shift. The differences in question may, however, disappear if the night worker is able to get enough sleep and can enjoy and digest his food.

In the four factories (F, G, H, and I) with fortnightly changes of shifts, the average hourly output in the first and second weeks after the change are compared in Table 2.

TABLE 2

RELATIVE HOURLY OUTPUT IN THE FIRST AND SECOND WEEKS AFTER THE CHANGE OF SHIFTS

\begin{tabular}{|c|c|c|c|c|c|c|c|}
\hline \multirow{3}{*}{$\begin{array}{l}\text { Factory } \\
\text { Group }\end{array}$} & \multirow{3}{*}{$\begin{array}{l}\text { No. of } \\
\text { Workers }\end{array}$} & \multicolumn{6}{|c|}{ Relative Hourly Output* } \\
\hline & & \multicolumn{3}{|c|}{ Day Shift } & \multicolumn{3}{|c|}{ Night Shift } \\
\hline & & $\begin{array}{c}1 \mathrm{st} \\
\text { Week }\end{array}$ & $\begin{array}{l}\text { 2nd } \\
\text { Week }\end{array}$ & Average & $\begin{array}{c}1 \text { st } \\
\text { Week }\end{array}$ & $\begin{array}{l}\text { 2nd } \\
\text { Week }\end{array}$ & Average \\
\hline $\begin{array}{l}\mathbf{F} \\
\mathbf{G} \\
\mathbf{H} \\
\mathbf{I}\end{array}$ & $\begin{array}{r}105 \\
72 \\
75 \\
53\end{array}$ & $\begin{array}{l}99 \cdot 22 \\
99 \cdot 48 \\
99 \cdot 83 \\
99 \cdot 76\end{array}$ & $\begin{array}{l}101 \cdot 13 \\
102 \cdot 77 \\
100 \cdot 67 \\
100 \cdot 00\end{array}$ & $\begin{array}{r}100 \cdot 17 \\
101 \cdot 13 \\
100 \cdot 25 \\
99 \cdot 88\end{array}$ & $\begin{array}{r}98 \cdot 22 \\
98 \cdot 52 \\
99 \cdot 50 \\
100 \cdot 82\end{array}$ & $\begin{array}{r}101 \cdot 43 \\
99 \cdot 23 \\
100 \cdot 00 \\
99 \cdot 42\end{array}$ & $\begin{array}{r}99 \cdot 83 \\
98 \cdot 87 \\
99 \cdot 75 \\
100 \cdot 12\end{array}$ \\
\hline \multicolumn{2}{|c|}{$\begin{array}{c}\text { Average of all } \\
\text { groups }\end{array}$} & $99 \cdot 57$ & $101 \cdot 14$ & $100 \cdot 36$ & $99 \cdot 26$ & $100 \cdot 02$ & $99 \cdot 64$ \\
\hline
\end{tabular}

*Expressed as percentages of the average hourly output on the day and night shifts combined.

On the day shift hourly output was higher in the second week than in the first week. The corresponding figures for the night shift were less definite. 
It seems highly probable that the lower rate of working in the first week on the day shift was due mainly to the after-effects of a fortnight on the night shift. In other words, the workers not only found it more difficult to maintain efficiency on the night shift but the effects of this effort in the form of reduced working capacity were carried forward to the following week on the day shift.

The results obtained from the three factories $(\mathrm{C}, \mathrm{J}$, and $\mathrm{K})$ where shifts were changed every month are given in Table 3.

TABLE 3

RELATIVE HOURLY OUTPUT* IN THE FIRST, SECOND, THIRD, AND FOURTH WEEKS AFTER THE CHANGE OF SHIFTS

\begin{tabular}{|c|c|c|c|c|c|c|c|}
\hline & \begin{tabular}{c|} 
Factory \\
Group
\end{tabular} & $\begin{array}{l}\text { No. in } \\
\text { Group }\end{array}$ & $\begin{array}{c}\text { 1st } \\
\text { Week }\end{array}$ & $\begin{array}{l}2 \text { nd } \\
\text { Week }\end{array}$ & $\begin{array}{c}\text { 3rd } \\
\text { Week }\end{array}$ & $\begin{array}{c}\text { 4th } \\
\text { Week }\end{array}$ & Average \\
\hline $\begin{array}{l}\text { Day } \\
\text { Shift }\end{array}$ & $\begin{array}{l}\mathbf{C} \\
\mathbf{J} \\
\mathbf{K}\end{array}$ & $\begin{array}{l}45 \\
41 \\
25\end{array}$ & $\begin{array}{l}99.98 \\
98.79 \\
99.47\end{array}$ & $\begin{array}{r}100 \cdot 61 \\
99.22 \\
100.97\end{array}$ & $\begin{array}{l}101.42 \\
100 \cdot 52 \\
101.04\end{array}$ & $\begin{array}{l}102 \cdot 51 \\
103 \cdot 34 \\
101 \cdot 36\end{array}$ & $\begin{array}{l}101 \cdot 13 \\
100 \cdot 47 \\
100 \cdot 71\end{array}$ \\
\hline \multicolumn{3}{|c|}{ Average of all groups } & $99 \cdot 41$ & $100 \cdot 27$ & $100 \cdot 99$ & $102 \cdot 40$ & $100 \cdot 77$ \\
\hline $\begin{array}{l}\text { Night } \\
\text { Shift }\end{array}$ & $\begin{array}{l}\mathbf{C} \\
\mathbf{J} \\
\mathbf{K}\end{array}$ & $\begin{array}{l}45 \\
41 \\
25\end{array}$ & $\begin{array}{l}98 \cdot 53 \\
98 \cdot 57 \\
99 \cdot 92\end{array}$ & $\begin{array}{l}98.98 \\
97.59 \\
99.02\end{array}$ & $\begin{array}{l}99.62 \\
98.62 \\
99.86\end{array}$ & $\begin{array}{r}98 \cdot 35 \\
103 \cdot 34 \\
98 \cdot 36\end{array}$ & $\begin{array}{l}98.87 \\
99.53 \\
99.29\end{array}$ \\
\hline \multicolumn{3}{|c|}{ Average of all groups } & $99 \cdot 01$ & $98 \cdot 53$ & $99 \cdot 37$ & $100 \cdot 02$ & $99 \cdot 23$ \\
\hline
\end{tabular}

*The figures are percentages of the average hourly output on the day and night shifts combined.

The day-shift figures show that the average hourly output increased in successive weeks after the change of shifts but the corresponding figures for the night shift revealed no definite tendency. The results accordingly support the view already expressed that the effects of night work impaired the rate of working on the subsequent day shift.

The output records as a whole show that output on night work was lower than on day work, though the advantage in favour of day work, measured in terms of percentage increases in efficiency, was never very large. There was also a fair amount of evidence that a period of two or four weeks on the night shift reduced the rate of working on the subsequent day shift. From these findings it follows that alternate periods of two or four weeks on day and night work are likely to be less productive than continuous day work.

Although most workers produced more output on the day shift than on the night shift, some (about one-third) worked just as well or even better on the night shift. Individual differences of this type should be taken into account when selecting men for night work.

\section{Absence from Work}

Since absence from work reflects, among other things, the effects of working conditions, it should provide some indication of the effects of night work and shift changes. A general comparison of the amount of absence on day and night work in different factory groups is given in Table 4. The figures refer to men, employed on various types of engineering, who changed shifts every fortnight.

TABLE 4

ABSENCE* OF MEN ON DAY AND NIGHT WORK

\begin{tabular}{|c|c|c|c|c|c|}
\hline \multirow[b]{2}{*}{ Factory } & \multirow{2}{*}{$\begin{array}{l}\text { Length } \\
\text { of } \\
\text { Period } \\
\text { (weeks) }\end{array}$} & \multicolumn{2}{|c|}{ Number Employed } & \multicolumn{2}{|c|}{ Percentage Absence } \\
\hline & & $\begin{array}{l}\text { Day } \\
\text { Shift }\end{array}$ & $\begin{array}{l}\text { Night } \\
\text { Shift }\end{array}$ & $\begin{array}{l}\text { Day } \\
\text { Shift }\end{array}$ & $\begin{array}{l}\text { Night } \\
\text { Shift }\end{array}$ \\
\hline $\begin{array}{l}\mathbf{F} \\
\mathbf{G} \\
\mathbf{L} \\
\mathbf{M} \\
\mathbf{N} \\
\mathbf{O} \\
\mathbf{P} \\
\mathbf{Q} \\
\mathbf{R} \\
\mathbf{S}\end{array}$ & $\begin{array}{l}28 \\
20 \\
32 \\
12 \\
36 \\
32 \\
12 \\
20 \\
24 \\
12\end{array}$ & $\begin{array}{r}2,953 \\
609 \\
2,431 \\
435 \\
857 \\
7,582 \\
507 \\
787 \\
739 \\
2,415\end{array}$ & $\begin{array}{r}1,097 \\
299 \\
1,196 \\
190 \\
708 \\
3,086 \\
305 \\
273 \\
270 \\
678\end{array}$ & $\begin{array}{r}10.37 \\
7.89 \\
9.67 \\
11.36 \\
8.73 \\
8.96 \\
8.25 \\
7.32 \\
8.30 \\
8.05\end{array}$ & $\begin{array}{l}7 \cdot 73 \\
6 \cdot 19 \\
8 \cdot 71 \\
9 \cdot 07 \\
8 \cdot 69 \\
6.93 \\
7 \cdot 62 \\
5.40 \\
5.53 \\
5.00\end{array}$ \\
\hline \multicolumn{2}{|c|}{ Average of 10 factorie } & . & .. & $8 \cdot 89$ & $7 \cdot 09$ \\
\hline
\end{tabular}

* Number of shifts lost expressed as a percentage of the number of shifts possible.

In all the factories absence was higher on the day shift than on the night shift. But the day-shift workers were more numerous than night-shift workers because the day shift included permanent day workers as well as day-shift workers of the two-shift system. Since most of the factory records of absence failed to distinguish between these two groups it was impossible to compare the absence of the same men on day and night work in alternate periods.

The inclusion of permanent day workers in the groups of two-shift workers was largely responsible for the higher rate of absence on the day shift since men who were unfit for night work were usually assigned to permanent day work.

.The general validity of these beliefs can be confirmed in different ways. In the first place, the excess of absence on the day shift in the different factories was directly related to the excess in the number of workers on the day shift. Secondly, in three factories where it was possible to abstract the absence records of the same men when employed on day and night work in alternate periods, absence on the day shift was only slightly higher than on the night shift.

Other factors which may have a bearing on the absence rates for day and night work are counter attractions outside the factory and the higher rate of payment for night work. For day-shift workers, for instance, any reluctance to go to work is likely to be reinforced by the many and varied opportunities for recreation and amusement but on the night shift the competing distractions are usually less numerous. The higher rate of payment for night work, may, on 
the other hand, have different effects on different people. Some will use the opportunity to earn as much as possible while others may act on the principle that the higher rate will compensate for time lost through an occasional absence.

In general, the absence figures for day and night work suggest that although factory records are likely to show an advantage in favour of night work, the advantage tends to become small or insignificant when comparisons are limited to the same workers employed on day and night work in alternate periods. The average weekly attendance on the day shift may also be adversely affected by the relatively high absence on Saturday morning and by competing interests outside the factory.

The figures in Table 5 refer to some of the factory groups included in Table 4 and show the percentage of shifts lost in the first and second weeks of the day shift and night shift respectively. Weeks affected by holidays were not included in these comparisons.

TABLE 5

ABSENCE* OF MEN IN THE FIRST AND SECOND WEEKS OF DAY AND NIGHT SHIFTS

\begin{tabular}{|c|c|c|c|c|c|c|c|}
\hline \multirow{3}{*}{ Factory } & \multirow{3}{*}{$\begin{array}{l}\text { Length } \\
\text { of } \\
\text { Period } \\
\text { (weeks) }\end{array}$} & \multicolumn{2}{|c|}{ No. Employed } & \multicolumn{4}{|c|}{ Percentage Absence } \\
\hline & & \multirow{2}{*}{$\begin{array}{c}\text { Day } \\
\text { Shift }\end{array}$} & \multirow{2}{*}{$\begin{array}{l}\text { Night } \\
\text { Shift }\end{array}$} & \multicolumn{2}{|c|}{ Day Shift } & \multicolumn{2}{|c|}{ Night Shift } \\
\hline & & & & $\begin{array}{c}\text { 1st } \\
\text { Week }\end{array}$ & $\begin{array}{c}\text { 2nd } \\
\text { Week }\end{array}$ & $\begin{array}{c}\text { 1st } \\
\text { Week }\end{array}$ & $\begin{array}{l}\text { 2nd } \\
\text { Week }\end{array}$ \\
\hline $\begin{array}{l}\mathbf{F} \\
\mathbf{L} \\
\mathbf{N} \\
\mathbf{O}\end{array}$ & $\begin{array}{l}28 \\
32 \\
36 \\
32\end{array}$ & $\begin{array}{r}2,953 \\
2,431 \\
857 \\
7,582\end{array}$ & $\begin{array}{r}1,097 \\
1,196 \\
708 \\
3,086\end{array}$ & $\begin{array}{r}10.44 \\
9.75 \\
9.05 \\
9.14\end{array}$ & $\begin{array}{r}10 \cdot 29 \\
9 \cdot 60 \\
8 \cdot 40 \\
8 \cdot 79\end{array}$ & $\begin{array}{l}7 \cdot 47 \\
8 \cdot 69 \\
8 \cdot 32 \\
6 \cdot 71\end{array}$ & $\begin{array}{l}7.98 \\
8.73 \\
9.07 \\
7 \cdot 14\end{array}$ \\
\hline
\end{tabular}

* Number of shifts lost expressed as a percentage of the number of shifts possible.

The general trend of these figures shows that absence was less in the second week of the day shift than in the first week of this shift. The differences, though small, were statistically significant in Factories $\mathbf{N}$ and $\mathbf{O}$ and approached significance in Factory F. On the night shift, absence was higher in the second week than in the first week of the fortnightly period, the difference being significant in Factories F, N, and $\mathrm{O}$.

Records of absence were also collected for a period of 16 weeks from 431 men in Factory $C$ who changed shifts regularly every four weeks. Each man had two periods of four weeks on the day shift and two similar periods on the night shift. The average amount of time lost in corresponding weeks on day and night shifts was :

\begin{tabular}{|c|c|c|c|c|c|c|}
\hline & \multicolumn{5}{|c|}{ Percentage Absence } \\
\hline & & $\begin{array}{c}\text { 1st } \\
\text { Week }\end{array}$ & $\begin{array}{l}\text { 2nd } \\
\text { Week }\end{array}$ & $\begin{array}{c}\text { 3rd } \\
\text { Week }\end{array}$ & $\begin{array}{c}\text { 4th } \\
\text { Week }\end{array}$ & Average \\
\hline $\begin{array}{l}\text { Day Shift } \\
\text { Night Shift }\end{array}$ & $\because$ & $\begin{array}{l}5 \cdot 38 \\
4 \cdot 48\end{array}$ & $\begin{array}{l}5.26 \\
4.59\end{array}$ & $\begin{array}{l}5 \cdot 10 \\
4 \cdot 83\end{array}$ & $\begin{array}{l}3.96 \\
5 \cdot 17\end{array}$ & $\begin{array}{l}4.93 \\
4.77\end{array}$ \\
\hline
\end{tabular}

Thus absence in the four successive weeks tended to decrease on the day shift and to increase on the night shift. These opposed tendencies, though based on the records of a comparatively small group, are similar to those obtained when shifts were changed every fortnight.

The most probable explanation of these tendencies is that night work impaired fitness or inclination for work, which resulted in a higher rate of absence in the later weeks of the night shift and in the earlier weeks of the following day shift. The decrease in absence in the second week of the day shift (Table 5) becomes more significant when it is remembered that, in three of the four factories, more than half the workers on this shift were employed on permanent day work and their absence figures would accordingly have a levelling effect on those of the first and second weeks of the day shift.

\section{Accidents}

An analysis of the accident records of 13,962 men employed in five factories showed that in each factory the accident rate was slightly higher on the night shift than on the day shift but in no case was the difference statistically significant. It is necessary to remember that night workers, as compared with day workers, are usually less inclined to go to the ambulance room for treatment of minor injuries, especially if the visit involves a walk in the dark and sometimes in rain.

It was also found that the accident rate in each factory varied on different days of the week but the general trends of the variations had little in common. The results accordingly suggest that in these groups the daily changes in accident frequency were due to local influences rather than to some common factor. In other words, the causes of the variations must be sought by detailed studies within each factory.

An accurate assessment of the parts played by speed of production, fatigue, boredom, and other factors in the causation of industrial accidents has yet to be made and a carefully devised and controlled series of experiments is necessary for this purpose. In the present state of our knowledge any attempt to explain the causes of the hourly and daily variations in accident frequency would be largely guesswork.

\section{Attitudes of Workers}

Although it is reasonable to assume that any major effects of night work and shift changes will be reflected in records of output, absence, and accidents, these objective indications give only one side of the picture and it is almost equally important to know. what the workers think and feel about night work. It is, for instance, often difficult or even impossible 
to persuade workers to agree to a change in the methods or conditions of work which, though supported by material evidence, yet fails to coincide with personal feelings and desires. Further, the opinions expressed by the workers are likely to reveal important and unsuspected aspects of the situation that are not disclosed by objective records. For these and other reasons it was decided to interview a sample of 50 men employed on the two-shift system in each of the three main factories, A, B, and $\mathrm{C}$, with a weekly, a fortnightly, and a monthly change of shifts respectively. The men were chosen at random from those who changed from the day shift to the night shift at regular intervals. It was thought that these samples, though small, would be big enough to show general tendencies and that, if necessary, a larger number could be interviewed at a later date. Each interview lasted from 30 to 60 minutes and was conducted in a private room provided by the management. The general aim and confidential nature of the interview were first explained to each worker and the main questions were preceded by reference to such routine details as age, length of service, and type of work. In order to preserve uniformity of procedure and to avoid discrepancies due to individual differences in assessing the results, the questions were standardized and all the interviews were conducted by the same investigator. Almost without exception, the workers showed the keenest interest in the questions.

Shift Preferences.-The men were asked which shift they preferred and to give reasons for their preferences. Almost all the men in each group preferred the day shift. Whether the men were employed on a weekly, fortnightly, or monthly change of shifts seemed to make little or no difference to their choice.

The day shift was preferred by $41 \%$ of the men because it left them free to do what they liked in the evening. They mentioned in particular the opportunities for recreation, amusement, and home life. About one-third said they felt better on the day shift and emphasized the advantages of the more normal and restful hours of sleep. A somewhat smaller proportion $(20 \%)$ spoke of better appetite and digestion and the value of meals at regular times.

The night shift was disliked by $34 \%$ of the men because they were unable to get enough sleep during the day and consequently felt tired and listless during the night. About $23 \%$ complained of the interference with personal habits and social life and approximately the same proportion referred to digestive trouble. The comparatively few men who liked or did not wholly dislike the night shift seemed to be influenced mainly by the higher rate of payment for night work. Although all the men had been employed for several years on the two-shift system, it is significant that a large proportion said they were still affected by the change in eating and sleeping habits.

The men were also asked if they preferred to change shifts weekly, fortnightly, monthly, or at longer intervals. A large majority $(66 \%$ in $A$, $78 \%$ in $\mathrm{B}$, and $68 \%$ in $\mathrm{C}$ ) preferred the existing system of shift changes. This agrees with previous findings, and is merely an example of the general principle that workers tend to like what they are used to. Most of the men who preferred a weekly change of shifts said that a week on the night shift was quite enough and a longer period would be too tiring. Some qualified their preferences by saying that a fortnightly change of shifts would give more time to get used to the interference with eating and sleeping habits but on balance they preferred the weekly change. Those who preferred the fortnightly change of shifts thought that a fortnight was better than a week from the standpoint of digestion and sleep and the same reason was given by those who liked a monthly change.

Fatigue.-Objective measures of industrial fatigue are usually based on the assumption that fatigue reduces the speed or accuracy of work and that this reduction is likely to be reflected most clearly in records of output and accidents. It may also be assumed that the cumulative effects of fatigue are sometimes partly or wholly responsible for absence from work. These objective measures, however, give only crude indications of the degree of fatigue and have been used as such in the present inquiry. Because of practical difficulties, no attempt was made to measure the variations in output throughout the day and, apart from the few hourly records of accidents, this study yielded no material indications of changes in working capacity during the daily hours of work.

Some subjective evidence on fatigue was obtained by questioning the men on their feelings of fatigue, and it was found that $8.7 \%$ felt most tired on the day shift; $83.3 \%$ on the night shift, and the remaining $8.0 \%$ noticed no difference. Those who felt most tired on the day shift said it was due to early rising and lateness in going to bed.

The replies to another question showed that feelings of fatigue at the end of work were more widespread and severe after night work than a fter day work. If fatigue increases as work proceeds, then feelings of fatigue should be most prominent 
in the last hour of work. This was found to be so on the day shift but not on the night shift where the peaks occurred between 3.0 a.m. and 4.0 a.m. or about three hours before the end of work. It seems probable that some of the fatigue felt at this stage was due to boredom which was afterwards dispelled by the increasing awareness of the approaching release from work.

The men who changed shifts fortnightly (Group B) and monthly (Group C) were asked if they felt most tired near the beginning or towards the end of the fortnight (Group B) or month (Group C). Their replies showed that men on a monthly change of shifts as compared with those on a fortnightly change included a larger proportion who felt most tired at the beginning of the period when on the day shift and at the end of the period when on the night shift. The inference seems to be that the monthly change of shifts, as compared with the fortnightly change, caused relatively more fatigue towards the end of the night-shift period, which, in some cases, was carried forward to the beginning of the dayshift period.

The few men who felt most fatigued towards the end of the day-shift period said it was due to "thinking about going on the night shift again", hence in these cases the feelings seemed to be due more to the dislike of night work than to actual fatigue. This attitude was also responsible for some of the increased fatigue felt at the beginning of the night-shift period, e.g.

"The night shift is lousy and at the beginning I dread the thought of going through a fortnight on night work."

"The beginning is the worst but it is depression as well as tiredness."

When shifts are changed fortnightly or monthly the incidence of fatigue is likely to be influenced by the intervening week-end break or breaks, usually from Saturday morning till Monday night. During these breaks most of the men revert to the normal time for sleep, but as a rule they get up very late on Sunday and later than usual on Monday and have no more rest before they leave for work on Monday night. A few "get up with the family" on Monday and rest in the afternoon. Some of the men found these week-end breaks and longer hours of sleep refreshing but others claimed that they made adaptation to night work still more difficult. The probable effect of these breaks on the physiological rhythms is clearly a matter of some importance and must be taken into account when assessing the merits and defects of night work and shift changes.

Meals. - The change in meal times during night work is believed to disturb digestion. It is also possible that, for some workers, the change may be an important factor in the aetiology of peptic ulcer. Of the 150 men who were interviewed, approximately $70 \%$ preferred to bring their own food rather than have the dinner provided by the factory and some of the remainder had the canteen dinner only occasionally. The proportions were roughly the same on both the day and night shifts.

Most of the non-users had tried the canteen meals and then decided in favour of food prepared at home which, in their view, was either superior, cheaper, or suited them better. Some admitted that they were fussy or faddish about food and a few disliked eating in public. A small number (4\%) said that the walk to the canteen and the queueing for food made eating " too much of a rush" so that they had no time to rest afterwards. About $25 \%$ of the men on the night shift " couldn't face the canteen dinner" and preferred lighter food.

Almost all the men brought sandwiches, which were eaten as snacks during the short breaks by those who had the canteen dinner. The remainder usually divided them roughly according to the time and length of the different breaks.

When asked about their appetites, $74 \%$ of the men said they enjoyed their food more when working on the day shift ; $3.3 \%$ had better appetites on the night shift, and the remaining $22.7 \%$ noticed no appreciable difference. The main reasons given for loss of appetite on the night shift were the "unnatural "meal times and stomach trouble.

About $70 \%$ of the men spent from 15 to 30 minutes over their main meal and the rest of the time in sitting, reading, talking, or dozing. Most of the remainder played cards or darts.

Whether shifts should be changed every week, fortnight, or month, will depend, amongst other things, on the effects of these changes on digestion and the time taken to get adapted to the change. The proportion of men who claimed that they settled down immediately to the new meal times after changing from night to day work was $61 \cdot 3 \%$. Most of the remainder took from .one to six days and a few took longer. After changing from day to night work, only $37 \cdot 3 \%$ seemed to be immune from the effects. A further $27 \%$ took from one to three days, $12.0 \%$ from four to six days, and most of the remainder never became completely adapted. Of the men in the latter category, 14 were employed for a week at a time on the night shift, six for a fortnight, and 15 for a month.

In view of the effect of shift changes on meal times, it seemed desirable to inquire whether these changes caused indigestion. The proportion was fairly small ( 31 out of 150 ) but 23 stated that they 
felt it more on the night shift than on the day shift. In 24 cases the attacks were occasional and irregular but in seven cases the indigestion seemed to be continuous. All the men stated that it had never been necessary to give up a job because of stomach trouble but a few (eight) had apparently been on the verge of doing so. It is necessary to remember, however, that the men interviewed were long-service workers and that the most serious cases had either left or been transferred to lighter work on a permanent day shift.

Of the 150 men in the three groups, 65 took patent medicines, usually every day or several times a week. The type of medicines taken suggested that they were in an attempt to counteract disorders of the stomach. Aspirin or similar tablets were also taken fairly frequently by $33 \%$ of the men.

Sleep.-In this inquiry, it was found that approximately $75 \%$ of the night shift men went to bed before 10 a.m. and about the same proportion got up between 3 p.m. and 6 p.m. The proportion who were satisfied with the amount of sleep was $57.7 \%$ but many of these added the qualifying remark that it was less refreshing than night time sleep.

The ability to sleep during the day was made more difficult by noises due to traffic, children, tradesmen, and wireless. About one-third of the men mentioned these disturbing noises while a further $24 \%$ attributed their wakefulness to " nerves", restlessness, fatigue, and bodily discomfort caused by the reversal of normal habits. A few men were able to sleep "like a $\log$ " whatever the conditions.

The men were questioned on the time taken to get adapted to the new sleeping habits involved by the change of shifts. Their replies showed that a large majority $(83.3 \%)$ adapted themselves immediately to the normal time for sleep after changing to the day shift. The corresponding figure for the night shift was $50 \%$. On the whole, the change in sleeping times seemed to be less disturbing than the change in meal times.

\section{General Considerations}

The output records collected in this survey showed no spectacular differences between the average rates of working on day and night shifts, neither were there any substantial changes in weekly efficiency within the shift cycles when shifts were changed every fortnight or every month. Yet there was little doubt that a majority of the workers found it more difficult to maintain their usual level of efficiency on the night shift than on the day shift.

Several of the tendencies shown by the output records were supported by the rates of absence on day and night work. Thus, after changing from night work to day work, attendance improved during the fortnight or month on the day shift. This, like the output records, suggests a process of recovery from the effects of night work and hence implies that night work imposed additional strains on the workers. Further evidence in support of this hypothesis was provided by the absence figures for the night shift which, unlike the day-shift figures, tended to increase in successive weeks.

The opinions of the workers on various aspects of night work were more illuminating than the factory records and it was rather surprising that what they felt seemed to have comparatively little effect on what they did. It must be remembered, however, that these men were employed on semi-automatic processes which tended to mask variations in working capacity. Also, their daily output was largely determined by long-established habits of work. Sometimes the cumulative effects of night work had repercussions on life outside the factory, and sometimes a stage was reached when a man had to be put on permanent day work but on the whole the feelings induced by night work seemed to be inadequately reflected in output. Feelings are often in conflict with necessities and a distaste for night work may be kept in abeyance by monetary needs. It is only when feelings reach a certain stage of intensity that they have an observable effect on rate of working.

Most of the men included in this survey mentioned the disturbing effects of changing from day work to night work on appetite and digestion and only a minority claimed that the change had little or no effect. The gradual process of adaptation to the change in meal times is, of course, one of the main arguments against a weekly change of shifts. It is interesting to note that more than $70 \%$ of the men, although employed on fairly heavy work, ate nothing but sandwiches while in the factory and many had only a light meal before starting work. There can be little doubt that, quite apart from the irregular meal times, the diet of most men was unbalanced and in need of some adjustment. As far as could be ascertained, they received no guidance on this subject either inside or outside the factory.

Many night workers referred to their inability to sleep well during the day, especially in the period immediately following the change of shifts. Even under the most favourable conditions, the reversal of normal habits tended to impair both the quantity and the quality of sleep but for many there were additional disturbances such as day-time noises. The inability to get enough sleep, especially during the first few days after changing shifts, is a further argument against a weekly change of shifts. 
The interference with sleep and digestion is perhaps the most obvious and expected effect of night work and shift changes. The human body is a complicated and balanced mechanism which, when properly nourished and rested, continues to function in a smooth and effortless manner. Any marked deviation from the normal mode of lite, such as the reversal of eating and sleeping habits, will naturally disturb the physiological rhythms and impose additional strains on the body mechanisms. Although the human machine is very adaptable there are limits to what it can bear and it is probably not surprising that some men were sorely tested by the change from day to night work. These physiological disturbances are, however, not the only adverse effects of night work ; they are sometimes equalled or exceeded by psychological stresses and strains caused by the disruption of social and family life. Most men and women have fairly fixed habits and dislike any change in their daily or weekly routine. Evening and week-end interests and activities are often the only high lights in a rather colourless existence and anything that interferes with these pleasures is usually strongly resented. Even more serious in their effects are the mental and emotional conflicts caused by the dislocation of normal married life. Several men referred to this problem and their comments varied from the comparatively mild opinion that " a week is quite long enough for the wife to be left alone at night " to admissions of strained or broken marital relations which were accentuated, if not caused, by night work.

This survey disclosed marked individual differences in susceptibility to the effects of night work and shift changes. While some experienced only mild discomfort and worked just as well on the night shift as on the day shift, others were more upset by night work. It is important to remember that the men included in this inquiry were longservice workers hardened by experience. They accordingly represented a selected group since those who were unable to bear the strains of night work had been transferred to permanent day work or discharged. An attempt was made to ascertain the number of men in each factory who, for health reasons, had been exempted from night work, but the records were incomplete, inaccessible, or nonexistent. The exclusion of these men from the present survey means that the adverse effects of night work and shift changes, as well as individual differences in response to these conditions, will be underestimated. Yet the findings show that some men were still unable to adapt themselves to night work and were obviously unsuitable for work on a two-shift system. In general, the results suggest that more attention should be given to the selection of men for night work and to the closer medical supervision of those selected.

With regard to the question as to whether shifts should be changed weekly, fortnightly or monthly, the evidence obtained in this inquiry, like that of earlier investigations, was inconclusive. While there can be little doubt that, for most workers, the change from day to night work had unfavourable effects on sleep and digestion it is almost equally certain that these effects had largely disappeared by the end of the first week after the change. This evidence in support of less frequent shift changes was, however, neutralized to some extent by the week-end break when most workers reverted to normal habits of life. Further, the results obtained in the present inquiry, like those recorded by Vernon in the 1914-18 war, show that absence tended to increase in successive weeks on the night shift. Vernon (1918) also found that, when shifts were changed every fortnight, output on the night shift was less in the second week than in the first week. It would appear, therefore, that the physiological evidence in favour of less frequent shift changes is not supported by the records of absence and output. Neither does it accord with the general dislike of night work and its interference with social and family life. On the whole, the balance of available evidence suggests that, so long as night work is necessary, a fortnightly change of shifts would be the most effective compromise from the standpoint of health, efficiency, and personal satisfaction, but further investigation is necessary before definite conclusions can be established. The only real solution to the problem is, of course, the abolition of night work except in times of emergency and in certain continuous processes. There is not the least doubt that night work is unpopular and, in the long run, is detrimental to health, efficiency, and the enjoyment of life. In every group of workers, some break down in health after a few weeks, months, or years of night work. These are the obvious casualties but it is reasonable to suppose that almost all workers are adversely affected in some degree and brought nearer to the point when the effects can no longer be ignored.

\section{Summary}

Output.-Output on night work was slightly less than on day work and this difference was equally noticeable whether shifts were changed weekly, fortnightly, or monthly.

When shifts were changed fortnightly, output on the day shift was higher in the second week than in the first week. An increase in output in successive 
weeks of the day shift was also noticeable when shifts were changed every month.

Although most of the men produced more on the day shift than on the night shift, some (about onethird) worked just as well or even better on the night shift.

Absence.-Although factory records are likely to show more absence on day work than on night work, mainly because of the employment on day work of men who are unfit for night work, there was little difference when comparisons were limited to the same men employed on day and night work in alternate periods.

When shifts were changed every two weeks absence on the night shift was higher in the second week than in the first week of the fortnight. On the day shift the opposite tendency was noticeable.

When shifts were changed every four weeks, the amount of absence in successive weeks also tended to increase on the night shift and to decrease on the day shift.

Attitudes.-Almost all the men preferred day work to night work mainly because it was believed to be better for health, output, and social life. The attitude to the frequency of shift changes was deter- mined more by custom and habit than by the intrinsic merits or defects of weekly, fortnightly, and monthly changes of shifts.

Feelings of fatigue, both during and after work, were more widespread and severe on night work than on day work.

Most of the men said that night work caused a loss of appetite and upset digestion. After changing to night work $27 \%$ of the men took from one to three days to settle down to the new meal times, $12 \%$ took from four to six days, and $23 \%$ needed longer. A tairly large proportion ( $43 \%$ ) took patent medicines, usually every day or several times a week.

Many night workers (42\%) claimed that they were unable to get enough sound sleep during the day. Almost $37 \%$ had less than six hours of slecp and $75 \%$ had less than eight hours. On the whole, changes in sleeping times seemed to be less disturbing than changes in meal times.

\section{REFERENCES}

Health of Munition Workers Committee (1917), Interim Report. Industrial Efficiency and Fatigue. (Cd. 8511.) H.M.S.O., London.

(1918). Final Report. Industrial Health and Efficiency. (Cd. 9065.) H.M.S.O., London.

Teleky, L. (1943). Industrial Medicine, 12, 758. Chicago.

Vernon H. M. (1918). An Investigation of the Factors Concerned in the Causation of Industrial Accidents. Health of Munition Workers Committee. Memo No 21 (Cd 9046). Mondon. 